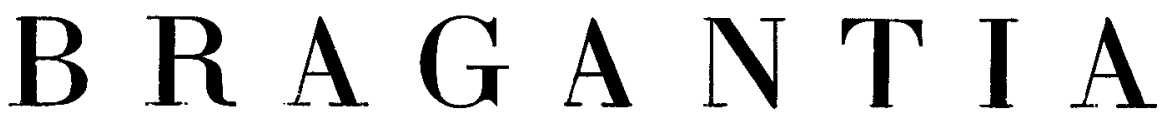

Boletim Científico do Instituto Agromômico do Estado de S. Paulo

Vol. 28

Campinas, maio de 1969

N. ${ }^{\circ} 15$

\title{
INFLUÊNCIA DA REGIÃO DE PLANTIO DO ARROZ SÔ- BRE A INFESTAÇÃO DA TRAÇA DOS CEREAIS, SITOTROGA CEREALELLA (OLIVIER) (LEPIDOPTERA GELECHIIDAE) (1)
}

CARLos Jorge Rossetto, engenheiro-agrônomo, Seção de Entomologia, Instituto Agronômico, A. ACCIOLI, engenheira-agrônoma, Departamento de Biologia, Secretaria da Agricultura do Ceará, L. B. Oliveira, estudante da Escola de Agronomia de Fortaleza, Ceará, e D. M. SouzA, engenheiro-agrônomo, Seção de Cereais, Instituto Agronômico $\left(^{2}\right)$

\section{SINOPSE}

Procurou-se verificar a influência da região e da irrigação na cultura do arroz sôbre a suscetibilidade posterior do grão armazenado ao ataque da traça.

Amostras de arroz com casca foram plantadas em quatro regiões diferentes do Estado de São Paulo, em culturas de várzea irrigada e de sequeiro. O produto, armazenado por um ano e meio em ambiente uniforme, foi submetido ao ataque da traça Sitotroga cerealella (Olivier).

Foi observado que o local de cultivo do arroz influencia sua suscetibilidade à infestação da traça dos cereais durante o armazenamento.

Os resultados mostraram que o arroz cultivado em sequeiro na região de Pindorama foi muito mais atacado pela traça que os cultivados nas outras regiões.

O teste de Scheffé mostrou que houve um contraste significativo entre o arroz de várzea de Pindamonhangaba, Campinas e Mococa e o de sequeiro de Pindorama e Campinas, mas não houve diferença significativa entre o arroz de várzea e o de sequeiro de Campinas.

O periodo entre a infestação do arroz em casca, em laboratório, e o início da emergência dos primeiros adultos foi de 23 dias.

(1) Trabalho apresentado na VII Reunión Latino-Americana de Fitotecnia, realizada em Maracay, Venezuela, de 17 a 23 de setembro de 1967 . Recebido para publicação em 24 de setembro de 1968.

(2) Eng.a-Agr.a A. Accioli e L. B. Oliveira, estagiários na Seção de Entomologia, Instituto Agronômico, em março de 1967 e janeiro e fevereiro de 1967, respectivamiente. 


\section{1 - INTRODUÇÃO}

A traça dos cereais, Sitotroga cerealella (Olivier), é uma praga dos cereais, no mundo inteiro. Informações sôbre a importância econômica, distribuição geográfica, taxonomia, morfologia e bioecologia dêsse inseto, podem ser obtidos na monografia de Carvalho (1). Com a finalidade de iniciar um programa de melhoramento do arroz contra essa praga, procurou-se determinar inicialmente qual a região paulista que produz os grãos mais suscetíveis a êsse inseto, pois é de grande importância determinar se uma variedade resistente a um inseto, produzida em Campinas, poderia ter comportamento diferente em outra região do Estado.

\section{2 - MATERIAL E MÉTODO}

Sementes - Usaram-se sementes de arroz em casca, de uma unica variedade (Dourado Agulha), da safra 1964/1965, plantada simultâneamente em cinco locais de quatro regiões do Estado:

1 - Campinas, cultura de várzea, em solo orgânico (várzea turfosa).

2 - Campinas, cultura de sequeiro, em solo Latossolo Roxo (terra roxa misturada).

3 - Mococa, cultura de várzea, em solo Podzólico Vermelho Amarelo-Orto (argiloso).

4 - Pindamonhangaba, cultura de várzea, em solo aluvial argiloso.

5 - Pindorama, cultura de sequeiro, em solo Podzolizado de I.ins e Marília (arenoso).

As datas de plantio, colheita e florescimento, a umidade relativa, precipitação, temperatura no periodo entre o florescimento e a colheita são sumarizadas no quadro 1 .

Insetos - Foram obtidos de milho da variedade Armour, de paiol da Estação Experimental "Theodureto de Camargo", em Campinas, e usados com 1 a 3 dias de idade. 
Outros materiais - Caixinhas plásticas de 2,5 $\times 4,7 \times 1,7 \mathrm{~cm}$, uma caixa de vidro de $24,5 \times 28,5 \times 7,0 \mathrm{~cm}$, com cobertura cie pano, e uma geladeira modificada para incubador, com temperatura de $31^{\circ} \mathrm{C}\left(+2^{\circ}\right)$ e $75 \%$ de umidade relativa.

Métodos - Depois de 18 meses de armazenamento em ambiente uniforme, na Seção de Entomologia, do Instituto Agronômico, foram pesadas, de cada local, duas séries de 10 amostras cle $8 \mathrm{~g}$ de sementes, perfazendo um total de 100 amostras para os cinco locais. As amostras foram acondicionadas nas caixinhas plásticas e colocadas no incubador, por 7 dias, para entrarem em equilíbrio higroscópico com o meio. Uma série de 50 amostras ( 10 de cada localidade) foi colocada na caixa de vidro, obedecendo um delineamento casualizado com 5 tratamentos (localidades de plantio) e 10 repetições.

Os adultos de $S$. cerealella foram coletados ao acaso, com o auxílio de um aspirador de pó, e liberados no interior da caixa de vidro coberta de pano, que continha as amostras que estavam distribuídas em blocos ao acaso no fundo da caixa, acondicionadas em caixinhas abertas.

A caixa foi mantida no escuro, durante 9 dias, para evitar efeitos fototrópicos sôbre a distribuição dos insetos na caixa, e no fim dêsse período retiraram-se todos os adultos infestantes. Cada caixinha de amostra foi então fechada, e os descendentes nascidos permaneceram confinados $\mathrm{e}$ foram tirados diàriamente e contados, até a emergência tornar-se quase nula, quando o experimento foi encerrado.

O experimento foi repetido duas vêzes. No primeiro, foram usados 800 adultos para a infestação, e observou-se a emergência dos descendentes até o $36 .^{\circ}$ dia após a infestação, que foi feita em 18 de janeiro de 1967. No segundo, foram usados 600 adultos na infestação, e observou-se a emergência dos descendentes até o $400^{\circ}$ dia após a infestação, feita no dia 22 de fevereiro de 1967.

\section{3 - RESULTADOS E DISCUSSÃO}

Os números totais de adultos nascidos de cada amostra estão representados no quadro 2. As emergências diárias dos adultos do arroz plantado nos cinco locais diferentes estão representados na figura 1. Esta figura mostra que o tamanho da população nascida do arroz cultivado no mesmo local foi relativamente constante nos dois experimentos. 


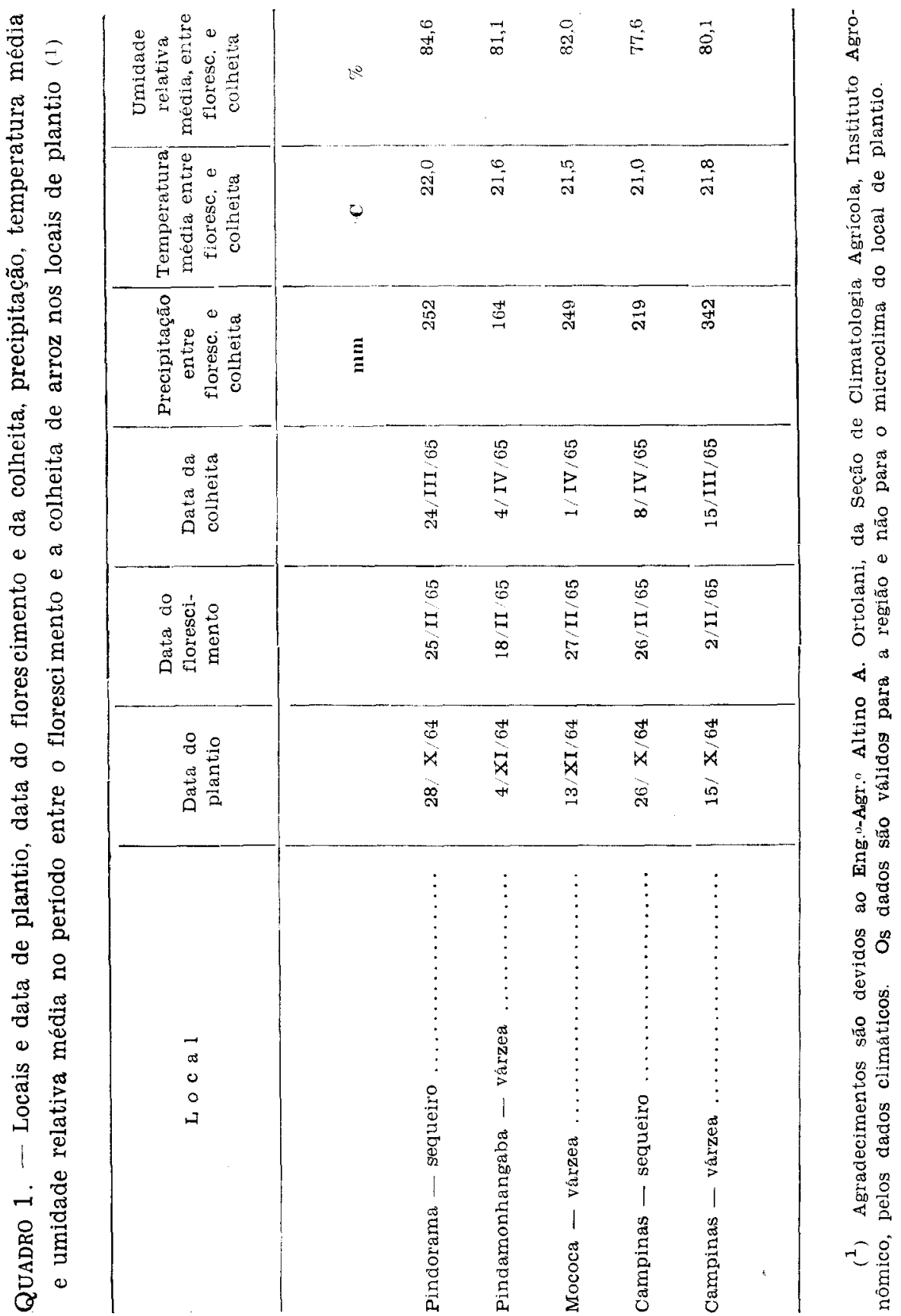




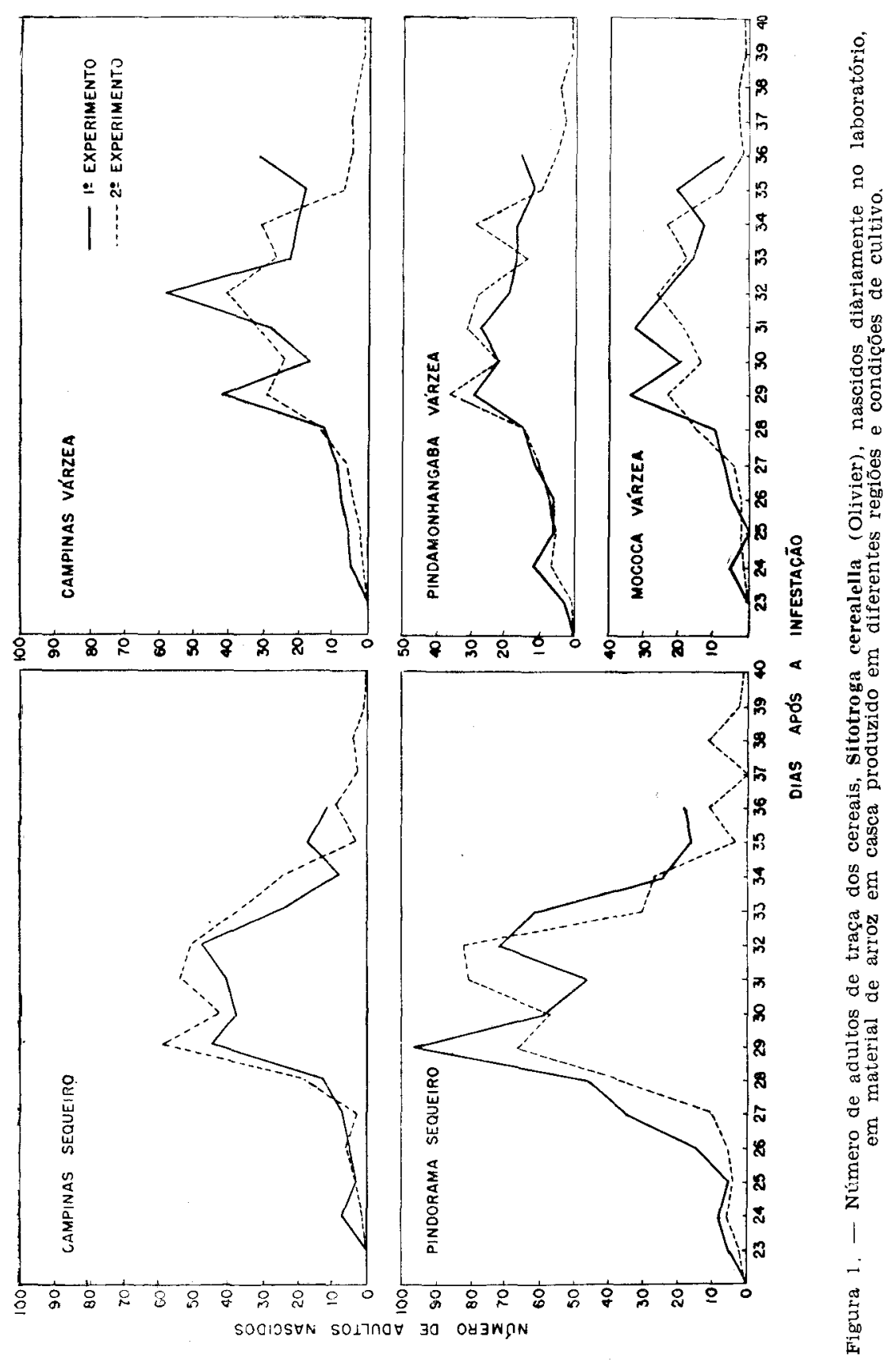


Os resultados mostraram que o local de plantio do arroz influencia a suscetibilidade do grão ao ataque da traça $\left(^{3}\right)$.

O arroz cultivado em Pindorama foi o mais atacado por S. cerealella.

O período da infestação até a emergência do primeiro adulto foi de 23 dias, para o arroz de Pindorama e Pindamonhangaba, o que constitui um recorde, para êsse inseto, e mostra que pode haver uma nova geração cada 25 dias, em condições favoráveis.

O teste de Scheffé indicou que houve um contraste, significativo a $1 \%(\mathrm{Y}=8,38 ; \mathrm{S}=3,59)$, entre o arroz de várzea de Pindamonhangaba, Campinas e Mococa e o arroz de sequeiro de Pindorama e Campinas, que foi mais infestado. Embora houvesse uma tendência para o arroz de várzea ser menos infestado que o de sequeiro, não se pode concluir que o seja, pois pode ter havido influência da localidade, no teste de Scheffé. Para a mesma localidade de Campinas o arroz de várzea não diferiu significativamente do de sequeiro.

A interação de três tipos gerais de fatôres pode regular a maior ou menor população de um inseto sôbre um hospedeiro: 1) fatôres da população do inseto; 2) fatôres da população do hospedeiro; e 3 ) fatôres do meio.

$\mathrm{Na}$ presente investigação foi medida exclusivamente a influência do meio ambiente natural, no qual o arroz foi cultivado, agindo unicamente de forma indireta, através da planta hospede:ra, sôbre a população da traça dos cereais. Os demais fatôres - a variedade de arroz, a população de inseto e a influência direta do meio - foram mantidos constantes.

O local de cultivo pode ter influenciado os grãos de arroz de duas maneiras: diretamente, através dos fatôres climáticos e doenças fúngicas, ou indiretamente, pela planta, através de fatôres edáficos ou climáticos. Pelo quadro 1 vê-se que a temperatura e a umidade de Pindorama foram um pouco mais elevadas no período de formação do grão, embora a diferença seja bem pequena. É possível que doenças fúngicas, como o bruzone, do arroz cultivado em Pindorama, tenham tornado o grão mais sus-

(3) Agradecimentos são devidos ao Eng.o-Agr.o Toshio Igue, da Seção de Técnica Experimental, pelo auxilio prestado à interpretaçāo da análise estatística. 
CARLOS JORGE ROSSETTO \& OUTROS

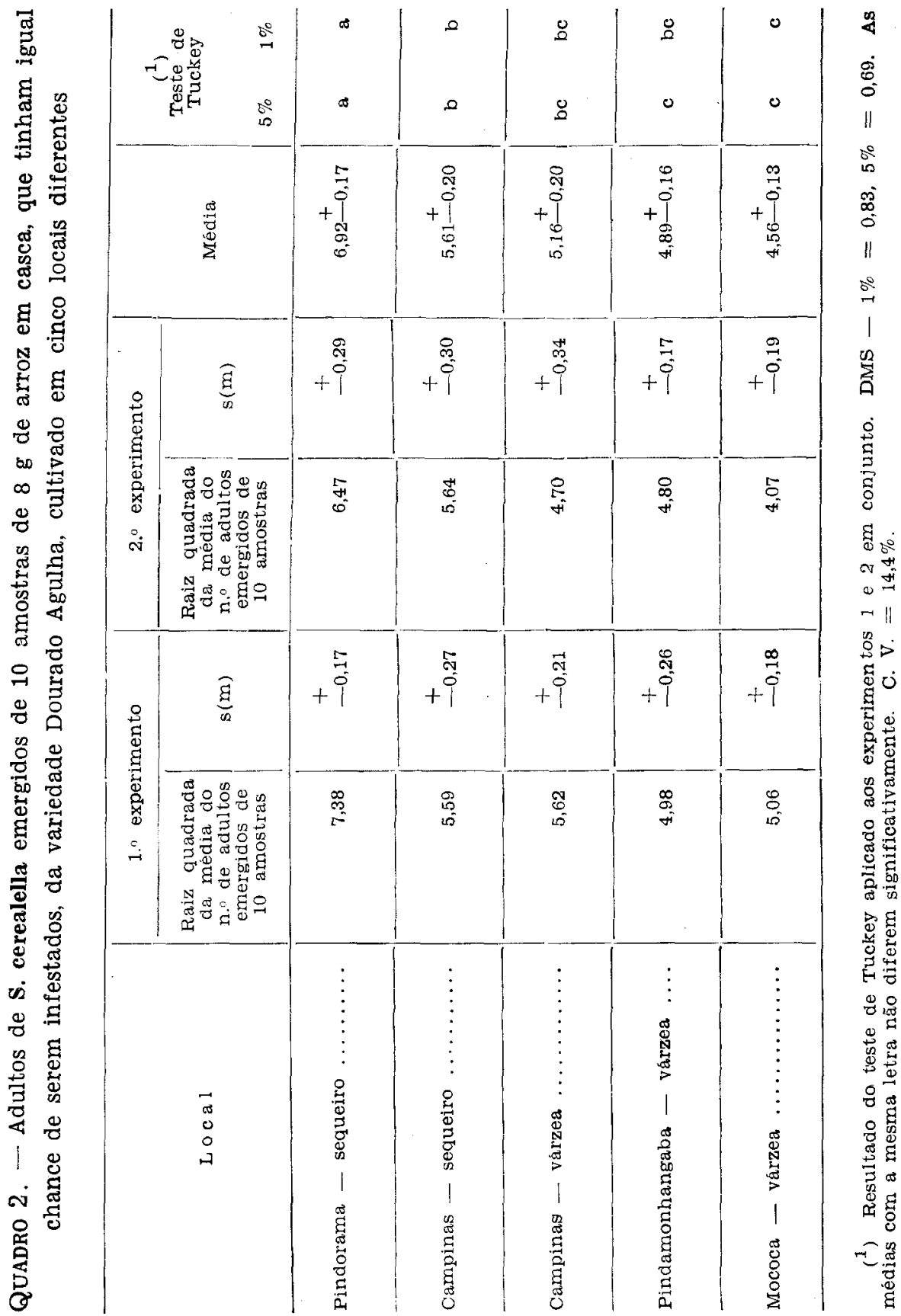


cetível ao ataque da traça, pois nos U.S.A. foi concluído que $S$. cerealella preferiu arroz infestado de fungo, principalmente Aspergiilus glaucus (2). Entretanto êste parece não ser o único fator influenciando a resistência do grão.

A nutrição da planta pode influenciar decisivamente a infestação das pragas (3), e é possivel que além da influência direta do meio sôbre o grão de arroz, através das doenças fúngicas, os fatôres edáficos tenham contribuído para tornar o arroz cultivado em Pindorama mais suscetivel.

\section{4 - CONCLUSÃO}

1 - Em condições favoráveis $S$. cerealella pode dar nova geração cada 25 dias em arroz armazenado em casca.

2 - O local de plantio do arroz influenciou a conservação do grão, nas condições do presente experimento. $O$ arroz cultivado em Pindorama foi o mais suscetível ao ataque da traça dos csreais, durante o armazenamento.

3 - Não houve diferença significante de suscetibilidade entre o arroz de várzea e o de sequeiro cultivados em Campinas. O teste de Scheffé indicou que houve um contraste entre o arroz de várzea de Pindamonhangaba, Mococa e Campinas, que foi menos infestado, e o arroz de sequeiro de Campinas e Pindorama, mais infestado. Embora o fator localidade possa ser a causa dessa diferença, houve uma tendência para o arroz de várzea ser menos infestado pela traça no armazenamento que o arroz de sequeiro.

INFLUENCE OF THE LOCAL OF RICE PLANTING UPON THE INFESTATION OF SITOTROGA CEREALELLA (OLIVIER) (LEPIDOPTERA GELECHIDAE)

\section{SUMMIARY}

It was investigated whether or not the local of cultivation of rice affects the posterior susceptibility to Sitotroga cerealella of the grain in storage.

Samples of rough rice from the same bulk of seeds, of the variety Dourado Agulha, were planted in four regions of the State of São Paulo, Pindamonhangaba paddy, Pindorama upland, Mococa paddy. Campinas 
paddy and Campinas upland. The rice, after having been harvested, was taken to Campinas where - after one year and half of storage under uniform conditions for all samples - it was tested for its susceptibility to the insect, by using samples of each local replicated 10 times randomly distributed inside of an insect cage. The progeny of insects of each sample was recorded daily. The trial was repeated twice.

The results showed that the local of cultivation has influence upon the posterior susceptibility of the grain in storage. The rice grown in Pindorama was more damaged by the pest than the rice grown in other regions.

There was no significant difference in susceptibility between the paddy and upland rice grown in Campinas. Scheffés test indicated that there was a strong contrast between the paddy rice grown in Pindamonhangaba, Mococa and Campinas and the upland rice grown in Pindorama and Campinas, the latter being more infested. Although the locality may account for this difference, there was a tendency for the upland rice to be much more infested in storage by $\mathbf{S}$. cerealella.

The period between infestation and the beginning of emergence of the first adults was of 23 days, showing that under favorable conditions this pest may give one generation each 25 days, in rough rice.

\section{LITERATURA CITADA}

1. CARVALHO, J. P. DE. A encomofauna dos produtos armazenados. Contribuição do método radiográfico para o estudo da Sitotroga cerealella (Oliv.) (Lepidoptera Gelechiidae). Lisboa, Junta de Investigações do Ultramar, 1963, 173p. (Estudos ensaios e documentos 109)

2. MisRA, C. P.; CHRISTENSEN, C. M. \& HODSON, A. C. The angoumois grain moth, Sitotroga cerealella, and storage fungi. J. econ. Ent. 54(5):1032-1033, 1961.

3. RODRIGUEZ, J. G. Nutrition of the host and reaction to pests. In: Biological and chemical control of plant and animal. Amer. Ass. Advance. Sci. 1960. Publ. 61. p.149-167. 